\section{(6) OPEN ACCESS}

\title{
Safety and effectiveness of drug-eluting stents in Chinese patients with coronary artery disease with off- and on-label indications: results from a single-centre registry
}

\author{
Xu-Min Hou, Wen-Zheng Han, Xing-Biao Qiu, Hui Chen, Wei-Yi Fang
}

Department of Cardiology, Shanghai Chest Hospital, Shanghai, China

\section{Correspondence to} Dr Xu-Min Hou, Department of Cardiology, Shanghai Chest Hospital, No 241 Huai Hai West Road, Shanghai 200030, China:

xumin_hou@hotmail.com

Received 15 April 2013 Revised 24 May 2013 Accepted 31 May 2013

\footnotetext{
To cite: Hou X-M, Han W-Z, Qiu X-B, et al. Heart Asia Published Online First: [please include Day Month Year] doi:10.1136/ heartasia-2013-010316
}

\author{
ABSTRACT \\ Background Off-label use of drug-eluting stents (DES) \\ is more common than on-label use and may be \\ associated with a persistently higher rate of adverse \\ angiographic and clinical outcomes.
}

Objective To evaluate the safety and effectiveness of unrestricted use of DES in everyday practice in a Chinese population.

Methods Between January 2004 and May 2009, we retrospectively enrolled 1209 consecutive patients who received DES in our single centre. $84.7 \%$ of patients were treated with sirolimus-eluting stents (SES) and $15.3 \%$ of patients were treated with paditaxel-eluting stents (PES).

Results $59.0 \%$ of patients $(n=713)$ were treated for off-label indications, with a significantly higher proportion of patients with previous coronary artery bypass grafting (CABG) $(6.2 \%$ vs $0.6 \%, p<0.001)$. There were no differences in coronary risk factors. During 6-66 months' follow-up, the rate of repeat target vessel revascularisation (TVR) was significantly higher in the off-label group ( $14.6 \%$ vs $9.7 \%, p=0.011)$. The risk of death and myocardial infarction were not statistically different with off-label from standard use. Multivariate logistic regression showed that the independent predictors of TVR were stent type (SES vS PES, $\mathrm{HR}=0.567,95 \% \mathrm{Cl} 0.395$ to 0.813$)$, previous CABG ( $H R=2.393,95 \% \mathrm{Cl} 1.440$ to 3.977$)$, the treatment of chronic total occlusion ( $\mathrm{HR}=2.786,95 \% \mathrm{Cl} 1.731$ to 4.484) and the treatment of left main lesion $(H R=1.854$, $95 \%$ Cl 1.022 to 3.363 ).

Conclusions In our local unselected cohort of Chinese people, off-label use of DES was safe in comparison with on-label use and associated with an excellent procedural success rate, but higher TVR.

\section{INTRODUCTION}

Since the first drug-eluting stent (DES) was approved by the Food and Drug Administration (FDA) for use in the USA in $2003,{ }^{1}$ it has become the most commonly used stent type in percutaneous coronary intervention (PCI). However, many uses of DES are not restricted to FDA-labelled recommendations (ie, off-label indications)-for example, they are used in bifurcation lesions, coronary artery bypass grafts, chronic total occlusions and long lesions requiring multiple overlapping stents. Observational studies have suggested an increased risk of complications after DES use in PCI of off-label lesions compared with indicated lesions. $^{2-5}$ During the European Society of
Cardiology meeting in September 2006, follow-up of the RAVEL and BASKET-LATE trials documented an increased risk of very late stent thrombosis with DES in comparison with bare-metal stent usage. Since then, DES efficacy and safety has become a hot topic, for patients and the media, and also for cardiologists and the FDA.

The number of PCIs performed in China has increased dramatically over the years. Published data from the Ministry of Health shows that 332992 PCI procedures were performed in 2011, with 91.4\% patients treated with DES. Complications occurred in only $0.7 \%$ of the cases and death in $0.3 \%$. Nowadays, physicians are inclined to use the 'best' available device for the individual patient even though it may not be evidence-based. DES use is at the discretion of the treating cardiologist and off-label use has become common practice. To date, the safety and effectiveness of using DES off-label have not been systematically evaluated within China. This study was undertaken to examine these topics in a retrospective, single-centre registry.

\section{METHODS}

Consecutive patients undergoing PCI in our centre from January 2004 to May 2009 were included in this analysis. Data on baseline demographic, clinical and angiographic characteristics and procedural characteristics during the index PCI, as well as the occurrence of death, myocardial infarction (MI) and the need for coronary-artery bypass grafting (CABG) during hospitalisation, were collected. DES use was considered 'off-label' if any of the following characteristics were present: restenotic lesion, bypass lesion (vein or arterial conduit), left main lesion, ostial lesion, bifurcation, or chronic total occlusion of more than 3 months, reference vessel diameter $<2.5$ or $>3.75 \mathrm{~mm}$ and lesion length $>30 \mathrm{~mm}$. Patients who had multivessel PCI or those in whom PCI was performed for acute MI were not considered off-label. ${ }^{3-9}$

The prespecified primary end point was a major adverse cardiac event (MACE), defined as a composite of all-cause death, non-fatal MI or target vessel revascularisation (TVR). MI was defined as the occurrence of two or more of the following: chest pain for $>20 \mathrm{~min}$, abnormal electrocardiographic changes (ST elevation of $\geq 1 \mathrm{~mm}$ in two contiguous leads or ST depression of $>-2 \mathrm{~mm}$ or new left bundle branch block), or increased cardiac biomarkers (creatine kinase $>3$ times the upper 
limits of the reference level or troponin $\mathrm{T}>0.1 \mathrm{ng} / \mathrm{mL}$ ). TVR was defined as repeat percutaneous or surgical revascularisation of the treated vessel, prompted by recurrence of angina symptoms or other evidence of ischaemia. Clinical follow-up was performed at $6,12,24,36,48$ and 60 months by telephone or office visit.

Statistical analysis was performed using SPSS V.16.0 (SPSS, Chicago, Illinois, USA). Categorical variables are expressed as number (\%) and continuous variables as mean \pm SD with $\mathrm{p}<0.05$ considered statistically significant. The $\chi^{2}$ test was used for comparison of categorical variables and the Student $t$ test for comparison of continuous variables between groups. The follow-up cumulative incidence rates of adverse events were estimated according to the Kaplan-Meier method and curves were compared using the log-rank statistic. Separate Cox regression analyses were performed to identify predictors of adverse events, using the clinical, angiographic and procedural variables listed in tables 1 and 2 .

\section{RESULTS}

Between January 2004 and May 2009, 1209 consecutive patients were retrospectively enrolled in our single centre. The percentage of patients treated with sirolimus-eluting stents (SES) was $84.7 \%$ and with paclitaxel-eluting stents (PES), $15.3 \%$. Based on our off-label use definitions, 713 (58.9\%) had at least one off-label criterion.

Patients' baseline characteristics are presented in table 1. Those who received stents for off-label indications had a greater likelihood of previous CABG $(6.2 \%$ vs $0.6 \%, \mathrm{p}<0.001)$ than those receiving stents for on-label indications. There were no differences in cardiac risk factors.

Lesion characteristics are presented in table 1. Off-label DES use was common in lesions whose length was $>30 \mathrm{~mm}$ (71.7\%), bifurcation lesions (26.8\%) and ostial lesions $(9.4 \%)$. There were no significant differences in type of stent $(\mathrm{p}=0.055)$ and multivessel PCI $(45.9 \%$ vs $41.3 \%, p=0.128)$. Although at lesion level, angiographic success was lower for off-label

Table 1 Baseline clinical and angiographic characteristics

\begin{tabular}{|c|c|c|c|}
\hline & On-label (n=496) & Off-label ( $n=713$ ) & p Value \\
\hline Age (years), mean $\pm S D$ & $65.32 \pm 10.41$ & $66.0 \pm 9.93$ & 0.252 \\
\hline Sex (male) & $341(68.8)$ & $478(67.0)$ & 0.532 \\
\hline \multicolumn{4}{|l|}{ Risk factors } \\
\hline Diabetes & $136(27.4)$ & $193(27.1)$ & 0.904 \\
\hline Hypertension & $317(63.9)$ & $474(66.5)$ & 0.338 \\
\hline Hyperlipidaemia & $141(28.4)$ & $177(24.8)$ & 0.166 \\
\hline Current smoking & $83(16.7)$ & $118(16.5)$ & 0.941 \\
\hline \multicolumn{4}{|l|}{ History } \\
\hline Stroke & $26(5.2)$ & $37(5.2)$ & 0.968 \\
\hline Previous MI & $114(23.0)$ & $177(24.8)$ & 0.461 \\
\hline Previous $\mathrm{PCl}$ & $65(13.1)$ & $117(16.4)$ & 0.114 \\
\hline Previous CABG & $3(0.6)$ & $44(6.2)$ & $<0.001$ \\
\hline LVEF, mean \pm SD & $41.97 \pm 23.69$ & $42.92 \pm 23.47$ & 0.657 \\
\hline \multicolumn{4}{|l|}{ Target vessel } \\
\hline LAD & $249(50.2)$ & $356(49.9)$ & \\
\hline LCX & $120(24.2)$ & $111(15.6)$ & \\
\hline RCA & $127(25.6)$ & $178(25.0)$ & \\
\hline LM & $0(0)$ & $45(6.3)$ & \\
\hline SVG & $0(0)$ & $23(3.2)$ & \\
\hline Type of stent & & & 0.055 \\
\hline SES & $431(86.9)$ & $592(83.0)$ & \\
\hline PES & $65(13.1)$ & $121(17.0)$ & \\
\hline Stent length $(\mathrm{mm})$, mean $\pm \mathrm{SD}$ & $22.05 \pm 5.40$ & $39.77 \pm 17.47$ & $<0.001$ \\
\hline Multivessel PCI & $205(41.3)$ & $327(45.9)$ & 0.128 \\
\hline \multicolumn{4}{|l|}{ Off-label indications } \\
\hline Lesion length $>30 \mathrm{~mm}$ & & $551(77.3)$ & \\
\hline Bifurcation & & $191(26.8)$ & \\
\hline Ostial lesion & & $67(9.4)$ & \\
\hline Total occlusion & & $67(9.4)$ & \\
\hline Lesion in LM & & $45(6.3)$ & \\
\hline \multicolumn{4}{|l|}{ Reference-vessel diameter } \\
\hline$<2.5 \mathrm{~mm}$ & & $15(2.1)$ & \\
\hline$>3.75 \mathrm{~mm}$ & & $59(8.3)$ & \\
\hline Restenotic lesion & & $32(4.5)$ & \\
\hline Graft lesion & & $23(3.2)$ & \\
\hline Angiographic success & $493(99.4)$ & $702(98.5)$ & 0.712 \\
\hline
\end{tabular}

Results are shown as number (\%) unless stated otherwise.

CABG, coronary-artery bypass grafting; LAD, left anterior descending artery; LCX, left circumflex artery; LM, left main stem; LVEF, left ventricular ejection fraction; MI, myocardial infarction; PCl, percutaneous coronary intervention; PES, paclitaxel-eluting stent; RCA, right coronary artery; SES, sirolimus-eluting stent; SVG, saphenous vein graft. 
Table 2 Major adverse cardiac events at follow-up

\begin{tabular}{|c|c|c|c|c|}
\hline & On-label $(n=496)$ & Off-label $(n=713)$ & Adjusted HR (95\% Cl) & $p$ Value \\
\hline 6 Months-death & $5(1.01)$ & $4(0.56)$ & 0.554 (0.148 to 2.074$)$ & 0.374 \\
\hline MI & $3(0.6)$ & $3(0.42)$ & 0.694 (0.140 to 3.454$)$ & 0.654 \\
\hline TVR & $7(1.41)$ & $11(1.54)$ & 1.095 (0.421 to 2.844$)$ & 0.853 \\
\hline MACE & $15(3.02)$ & $18(2.52)$ & $0.645(0.322$ to 1.291$)$ & 0.212 \\
\hline 12 Months-death & $8(1.61)$ & $7(0.98)$ & 0.605 (0.218 to 1.679$)$ & 0.329 \\
\hline $\mathrm{Ml}$ & $10(2.02)$ & $8(1.12)$ & 0.551 (0.216 to 1.407$)$ & 0.207 \\
\hline TVR & $15(3.02)$ & $50(7.01)$ & $1.858(1.032$ to 3.344$)$ & 0.036 \\
\hline MACE & $33(6.65)$ & $65(9.12)$ & 1.407 (0.910 to 2.176$)$ & 0.123 \\
\hline 24 Months-death & $10(2.02)$ & $16(2.24)$ & 1.116 (0.502 to 2.479$)$ & 0.788 \\
\hline MI & $13(2.62)$ & $13(1.82)$ & 0.690 (0.317 to 1.501$)$ & 0.347 \\
\hline TVR & $26(5.24)$ & 71 (9.96) & 1.999 (1.256 to 3.182$)$ & 0.003 \\
\hline MACE & $49(9.88)$ & $100(14.03)$ & 1.488 (1.035 to 2.139$)$ & 0.031 \\
\hline 36 Months-death & $15(3.02)$ & $28(3.93)$ & 1.311 (0.693 to 2.481$)$ & 0.404 \\
\hline $\mathrm{Ml}$ & $15(3.02)$ & $26(3.65)$ & 1.214 (0.636 to 2.316$)$ & 0.556 \\
\hline TVR & $35(7.06)$ & $88(12.34)$ & 1.855 (1.231 to 2.794$)$ & 0.003 \\
\hline MACE & $65(13.1)$ & $142(19.92)$ & 1.649 (1.199 to 2.269$)$ & 0.002 \\
\hline 48 Months-death & $21(4.23)$ & $35(4.91)$ & 1.168 (0.671 to 2.031$)$ & 0.583 \\
\hline Ml & $18(3.63)$ & $30(4.21)$ & 1.166 (0.643 to 2.117$)$ & 0.612 \\
\hline TVR & $44(8.87)$ & $100(14.03)$ & 1.583 (1.088 to 2.305$)$ & 0.016 \\
\hline MACE & $83(16.73)$ & $165(23.14)$ & 1.498 (1.118 to 2.008$)$ & 0.007 \\
\hline 60 Months-death & $23(4.64)$ & $36(5.05)$ & 1.094 (0.640 to 1.869$)$ & 0.744 \\
\hline MI & $20(4.03)$ & $31(4.35)$ & 1.082 (0.609 to 1.921$)$ & 0.788 \\
\hline TVR & $48(9.68)$ & $104(14.59)$ & 1.594 (1.109 to 2.292 ) & 0.011 \\
\hline MACE & $91(18.35)$ & $171(23.98)$ & 1.404 (1.056 to 1.867$)$ & 0.019 \\
\hline
\end{tabular}

Results are shown as number (\%).

MACE, major adverse clinical events; MI, myocardial infarction; TVR, target vessel revascularisation.

(98.5\%) use compared with on-label (99.4\%), the difference was not statistically significant.

\section{Outcomes at follow-up}

Median durations of follow-up were 36 months (range 1-66 months). At the 6-month follow-up, those receiving DES for off-label indications had a lower death rate $(0.56 \%$ vs $1.01 \%$, $\mathrm{p}=0.374)$ and $\mathrm{MI}(0.42 \%$ vs $0.6 \%, \mathrm{p}=0.654)$ than patients with on-label indications, but the difference was not statistically significant. There remained no significant difference in death and MI between the groups for 1-year follow-up (table 2). However, a statistically significant early increased risk of TVR was found for off-label use at 1-year follow-up compared with on-label use $(7.01 \%$ vs $3.02 \%, p=0.036)$ and it remained so up to the 5 -year of follow-up. At the 5 th year of follow-up, the incidence of TVR was much higher in the off-label group $(14.59 \%$ vs $9.68 \%$, $\mathrm{p}=0.011)$, whereas the incidence of MI $(4.35 \%$ vs $4.03 \%$, $\mathrm{p}=0.788)$ and death $(5.05 \%$ vs $4.64 \%, \mathrm{p}=0.744)$ were similar in off-label and on-label treated patients. As a result of the reductions in repeat intervention for on-label DES use, the composite end point of MACE was significantly less in that group than with off-label use (18.35\% vs 23.98\%, p=0.019) (Figure 1).

The independent predictors of death were age $>70$ years $(\mathrm{HR}=4.264,95 \%$ CI 2.540 to 7.160$)$, presence of thrombus $(\mathrm{HR}=4.716,95 \%$ CI 2.544 to 8.740$)$, previous PCI $(\mathrm{HR}=2.205$, $95 \%$ CI 1.235 to 3.934$)$ and ostial lesion treatment $(\mathrm{HR}=2.416$, 95\% CI 1.161 to 5.217). The independent predictors of TVR were stent type (SES vs PES, HR=0.567, 95\% CI 0.395 to 0.813 ), previous CABG ( $\mathrm{HR}=2.393,95 \%$ CI 1.440 to 3.977$)$, the treatment of chronic total occlusion $(\mathrm{HR}=2.786,95 \% \mathrm{CI} 1.731$ to 4.484) and the treatment of left main lesion ( $\mathrm{HR}=1.854,95 \% \mathrm{CI}$ 1.022 to 3.363$)$. The independent predictors of MI were age
$>70$ years $(\mathrm{HR}=2.167,95 \%$ CI 1.290 to 3.639), hyperlipidaemia $(\mathrm{HR}=2.188,95 \%$ CI 1.301 to 3.680$)$, previous $\mathrm{MI}(\mathrm{HR}=1.843$, 95\% CI 1.083 to 3.173 ) (table 3). After adjustment for lesion classification, baseline clinical and angiographic differences, there was no significant detrimental impact on MI, death/MI, or TVR during the follow-up with on-label or off-label use of DES.

Use of clopidogrel and aspirin was more than $85 \%$ in both groups at 12 months (table 4). Similarly, at 12 months almost $80 \%$ of the study patients were receiving a statin, but the percentages receiving an ACE inhibitor (70\%) or a $\beta$ blocker $(60 \%)$ were lower.

\section{DISCUSSION}

In this report, we presented long-term clinical outcomes after the use of DES in an all-comers registry. DES in this population was found to be safe with no increase in all-cause death and non-fatal MI in our off-label indication cohort compared with the on-label group. The high rate of MACE seen in the off-label group was due to a significant difference in TVR at a medium of 3 years of follow-up, which reflected the complex nature of the 'off-label' population.

Our study confirms the findings reported by Beohar et al and Win $e t a l^{5}$ - that off-label use of DES is common. In our study, 59\% of patients had their stent usage classified as offlabel. In the study by Beohar et al, $47 \%$ of patients received a DES for either an off-label or an untested indication and in the study by Win et al, 55\% of patients had at least one off-label characteristic. Furthermore, the 1-year TVR rates in the off-label group $(7.01 \%)$ in our study are similar to those reported by Beohar et al (7.6\%) and Win et al (6.3\%).

Evidence from randomised trials and registries exists showing the benefit of DES in many off-label indications, which supports 

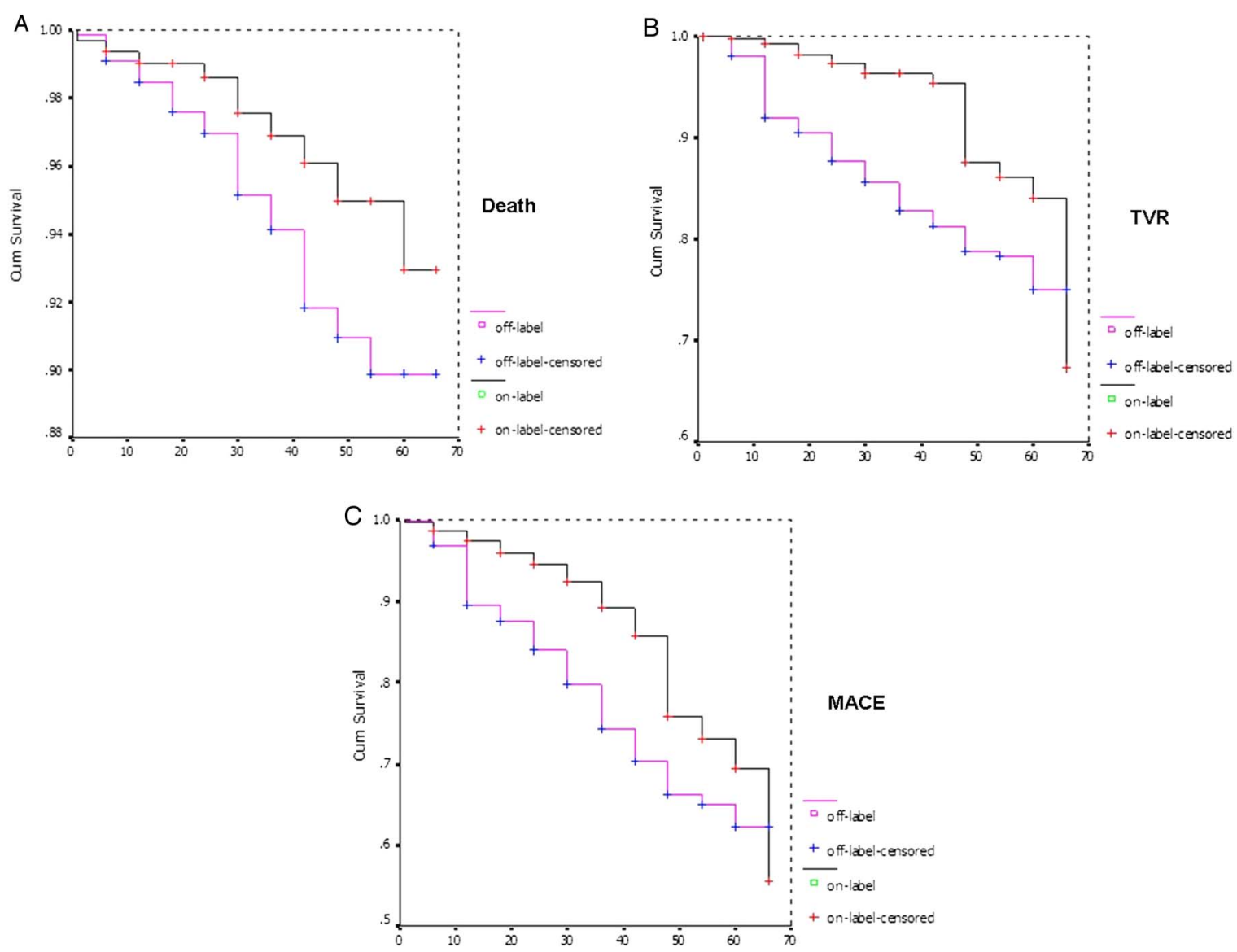

Figure 1 Kaplan-Meier curves for outcome according to label indication. MACE, major adverse cardiac events.

the findings of this study. Our data indicate that PCI of off-label lesions is not associated with worse late outcomes for death and MI compared with PCI of on-label lesions. Although off-label

Table 3 Independent clinical predictors of clinical outcomes

\begin{tabular}{lllr}
\hline Predictors & HR & $95 \%$ Cl & p Value \\
\hline Death & & & \\
$\quad$ Age $>70$ & 4.264 & 2.540 to 7.160 & $<0.001$ \\
$\quad$ Previous PCI & 2.205 & 1.235 to 3.934 & 0.007 \\
$\quad$ Thrombotic lesion & 4.716 & 2.544 to 8.740 & $<0.001$ \\
$\quad$ Ostial lesion & 2.416 & 1.161 to 5.217 & 0.019 \\
TVR & & & \\
$\quad$ Stent type (SES vs PES) & 0.567 & 0.395 to 0.813 & 0.002 \\
$\quad$ Previous CABG & 2.393 & 1.440 to 3.977 & 0.001 \\
$\quad$ Chronic total occlusion & 2.786 & 1.731 to 4.484 & $<0.001$ \\
$\quad$ Left main lesion & 1.854 & 1.022 to 3.363 & 0.042 \\
MI & & & \\
$\quad$ Age $>70$ & 2.167 & 1.290 to 3.639 & 0.003 \\
$\quad$ Hyperlipidaemia & 2.188 & 1.301 to 3.680 & 0.003 \\
$\quad$ Previous MI & 1.843 & 1.083 to 3.173 & 0.024 \\
MACE & & & \\
$\quad$ Age $>70$ & 1.646 & 1.272 to 2.127 & $<0.001$ \\
Previous CABG & 1.989 & 1.297 to 3.049 & 0.002 \\
$\quad$ Chronic total occlusion & 2.265 & 1.491 to 3.440 & $<0.001$ \\
$\quad$ Hyperlipidaemia & 1.383 & 1.062 to 1.802 & 0.016 \\
Left main lesion & 1.738 & 1.044 to 2.895 & 0.034 \\
\hline CABG, cor
\end{tabular}

CABG, coronary-artery bypass grafting; MACE, major adverse cardiac events; $\mathrm{MI}$, myocardial infarction; PCI, percutaneous coronary intervention; PES, paclitaxel-eluting stent; SES, sirolimus-eluting stent; TVR, target vessel revascularisation. use involved more complex anatomy, including multi-lesion stenting, a high degree of angiographic success occurred in patients receiving DES for off-label (98.5\%) and on-label (99.4\%) indications. This indicates widespread proficiency and stent performance in treating a variety of lesions and clinical subtypes. Since the patient population of this study was gathered between 2006 and 2009, improvements in stent design and technical refinement in performing PCI might also have contributed to the results. Another possible explanation for our findings may relate to the augmentation of ancillary medical treatment-almost $85 \%$ of the study patients were compliant with at least 1 year dual antiplatelet therapy (DAPT). The impact of prolonged DAPT is an important consideration for the safety of DES. Previous data have indicated that premature discontinuation of antiplatelet therapy after use of DES contributes to stent thrombosis. ${ }^{10}$ Moreover, prolonged DAPT with aspirin and clopidogrel has been associated with a reduced risk of death or MI after use of DES. ${ }^{11}$

Table 4 Medication at 1-year follow-up

\begin{tabular}{llll}
\hline & On-label $(\mathbf{n = 4 9 6 )}$ & Off-label use $(\mathbf{n = 7 1 3 )}$ & $\mathbf{p}$ Value \\
\hline Aspirin & $442(89.1)$ & $634(88.9)$ & 0.916 \\
Clopidogrel & $424(85.5)$ & $607(85.1)$ & 0.866 \\
Statin & $416(83.9)$ & $585(82.0)$ & 0.409 \\
$\beta$ Blocker & $300(60.5)$ & $415(58.2)$ & 0.428 \\
ACE inhibitor & $353(71.2)$ & $493(69.1)$ & 0.450 \\
\hline \multicolumn{7}{l}{ Results are shown as number (\%). }
\end{tabular}


Significantly more MACE occurred in the off-label group than in the on-label group. This finding was expected since offlabel indications usually represent more complex lesions and are probably associated with more severe degree of coronary atherosclerosis and with higher cardiovascular risks. Our study shows that the overall poorer outcome with off-label than with on-label use is related to TVR during long-term follow-up. In addition, we found that the increased hazard of TVR is associated with PES usage, but not with SES. Recent large trials of first-generation SES and PES such as REALITY, ${ }^{12}$ SORT OUT II, ${ }^{13}$ SIRTAX LATE ${ }^{14}$ and PROSIT ${ }^{15}$ failed to show a significant difference in target lesion revascularisation (TLR)/TVR during long-term follow-up. Kufner et $a l^{16}$ reported a meta-analysis in diabetic patients, based on six randomised trials including 1183 patients. They found that SES were associated with a significant reduction in the risk of TLR $(\mathrm{HR}=0.65(0.47-0.91), \mathrm{p}=0.01)$. For our study, this difference in outcome between PES and SES could be related to the differences in drug release kinetics, differential recovery of the cell cycle of quiescent smooth muscle cells and differences in vascular healing in response to the two different drugs or polymers used in the respective stent designs. $^{17-20}$

Our study has some limitations. First, it is based on an observational registry and is a single-centre retrospective study; such a study design has inherent limitations. Second, the number of patients who received PES in our study was relatively small, compared with those receiving SES. Hence, while the observed difference in the results between the two stent choices might be real, we cannot exclude the possibility that this finding occurred by chance alone, or is due to selection bias for a particular DES as stent choice was not randomised. Lastly, we used all-cause mortality rather than cardiac mortality as an end point. Perhaps the latter might be a more relevant measurement of differences between the two groups of study subjects.

\section{CONCLUSIONS}

The main findings of our study were that DES were associated with an excellent procedural success rate and were safe and efficacious in a large cohort of relatively non-selected Chinese patients with coronary artery disease. In addition, there was no significant difference in outcome between the on-label group and the off-label group.

Contributors $\mathrm{X}-\mathrm{MH}$ : conception and design, drafting the article. W-ZH: analysis and interpretation of data. X-BQ and HC: acquisition of data.W-YF: final approval of the version published.

Competing interests None.

Patient consent Obtained.

Ethics approval Ethics committee.

Provenance and peer review Not commissioned; externally peer reviewed.

Open Access This is an Open Access article distributed in accordance with the Creative Commons Attribution Non Commercial (CC BY-NC 3.0) license, which permits others to distribute, remix, adapt, build upon this work non-commercially, and license their derivative works on different terms, provided the original work is properly cited and the use is non-commercial. See: http://creativecommons.org/ licenses/by-nc/3.0/

\section{REFERENCES}

1 Abbott JD, Voss MR, Nakamura M, et al. Unrestricted use of drug-eluting stents compared with bare-metal stents in routine clinical practice: findings from the National Heart, Lung and Blood Institute Dynamic Registry. J Am Coll Cardiol 2007;50:2029-36.

2 Applegate RJ, Sacrinty MT, Kutcher MA, et al. "Off-label" stent therapy 2-year comparison of drug-eluting versus bare-metal stents. J Am Coll Cardiol 2008;51:607-14.

3 Marroquin OC, Selzer F, Mulukutla SR, et al. A comparison of baremetal and drug-eluting stents for off-label indications. $N$ Engl J Med 2008;358:342-52.

4 Ramsdale DR, Rao A, Asghar 0, et al. Late outcomes after drug-eluting stent implantation in "real-world" clinical practice. J Invasive Cardiol 2008; 20:493-500.

5 Win HK, Caldera AE, Maresh K, et al. Clinical outcomes and stent thrombosis following off-label use of drug-eluting stents. JAMA 2007;297:2001-9.

6 Harjai KJ, Orshaw P, Boura J, et al. Comparison of long-term outcomes of bare metal or drug-eluting stent implantation in standard versus off-label coronary narrowings. Am J Cardiol 2009;103:1537-45.

7 Ribera A, Ferreira-González I, Del Blanco BG, et al. Drug-eluting stents for off-label indications in real clinical world: Evidence based or 'intuition' based clinical practice? Int J Cardiol 2013;64:116-22.

8 Beohar N, Davidson CJ, Kip KE, et al. Outcomes and complications associated with off-label and untested use of drug-eluting stents. JAMA 2007;297:1992-2000.

9 Roy P, Buch AN, Javaid A, et al. Impact of "off-label" utilization of drug-eluting stents on clinical outcomes in patients undergoing percutaneous coronary intervention. Am J Cardiol 2008;101:293-9.

10 lakovou I, Schmidt T, Bonizzoni E, et al. Incidence, predictors and outcome of thrombosis after successful implantation of drug-eluting stents. JAMA 2005;293:2126-30.

11 Eisenstein EL, Anstrom KJ, Kong DF, et al. Clopidogrel use and long-term clinical outcomes after drug-eluting stent implantation. JAMA 2007;297:159-68.

12 Morice MC, Colombo A, Meier B, et al. Sirolimus- vs paclitaxel-eluting stents in de novo coronary artery lesions: the REALITY trial: a randomized controlled trial. JAMA 2006:295:895-904.

13 Galløe AM, Thuesen L, Kelbaek H, et al. Comparison of paclitaxel- and sirolimus-eluting stents in everyday clinical practice: the SORT OUT II randomized trial. JAMA 2008;299:409-16.

14 Räber $\mathrm{L}$, Wohlwend $\mathrm{L}$, Wigger $\mathrm{M}$, et al. Five-year clinical and angiographic outcomes of a randomized comparison of sirolimus-eluting and paclitaxel-eluting stents: results of the Sirolimus-Eluting Versus Paclitaxel-Eluting Stents for Coronary Revascularization LATE trial. Circulation 2011;123:2819-28.

$15 \mathrm{Kim} \mathrm{HS}$, Lee JH, Lee SW, et al. Long-term safety and efficacy of sirolimus- vs. paclitaxel-eluting stent implantation for acute ST-elevation myocardial infarction: 3-year follow-up of the PROSIT trial. Int J Cardiol 2011;47:253-7.

16 Kufner $S$, de Waha A, Tomai $F$, et al. A meta-analysis of specifically designed randomized trials of sirolimus-eluting versus paclitaxel-eluting stents in diabetic patients with coronary artery disease. Am Heart J 2011;162:740-7.

17 Windecker S, Remondino A, Eberli FR, et al. Sirolimus-eluting and paclitaxel-eluting stents for coronary revascularization. N Engl J Med 2005;353:653-62.

18 Kereiakes DJ, Kuntz RE, Mauri L, et al. Surrogates, substudies and real clinical end points in trials of drug-eluting stents. J Am Coll Cardiol 2005;45:1206-12.

19 ten Berg JM, Kelder JC, Suttorp MJ, et al. Influence of planned six-month follow-up angiography on late outcome after percutaneous coronary intervention: a randomized study. J Am Coll Cardiol 2001;38:1061-9

20 Ruygrok PN, Melkert R, Morel MA, et al. Does angiography six months after coronary intervention influence management and outcome? J Am Coll Cardiol 1999;34:1507-11. 